\title{
AÇÃO DO 1-METILCICLOPROPENO (1-MCP) NA VIDA DE PRATELEIRA DA BANANA 'MAÇÃ ' $'$
}

\author{
ANA CARLA MARQUES PINHEIRO², EDUARDO VALÉRIO DE BARROS VILAS BOAS ${ }^{3}$, \\ CAROLINE TEIXEIRA MESQUITA ${ }^{4}$
}

\begin{abstract}
RESUMO - Objetivou-se avaliar o efeito do 1-metilciclopropeno (1-MCP), em diferentes concentrações, sobre a vida pós-colheita e sob as variáveis associadas aos atributos de qualidade de banana 'Maçã'. Frutos verde-maturos foram submetidos a cinco concentrações de 1-MCP (0; 50; 100; 150 e $\left.200 \eta \mathrm{L} . \mathrm{L}^{-1}\right)$, por 12 horas, e foram analisados durante o amadurecimento sob condição ambiente $\left(20 \pm 1^{\circ} \mathrm{C}\right.$ e $80 \pm 5 \%$ UR). O tratamento com $50 \eta \mathrm{L} . \mathrm{L}^{-1}$ de 1-MCP atrasou o início do amadurecimento das bananas em aproximadamente 8 dias, baseando-se nas primeiras mudanças de coloração da casca, enquanto os tratamentos 100; 150 e $200 \eta \mathrm{L} . \mathrm{L}^{-1}$ atrasaram-no em aproximadamente 10 dias. Observou-se, durante o amadurecimento, o amaciamento dos frutos, associado à conversão de amido em açúcares e ao aumento na solubilização péctica e na atividade da pectinametilesterase (PME) e

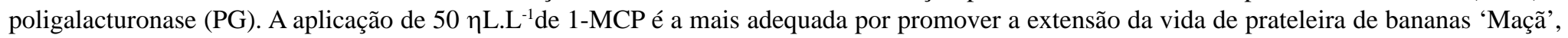
preservando sua qualidade com base nas análises de açúcares solúveis totais, pectinas total e solúvel, firmeza e aparência externa ao final do armazenamento.
\end{abstract}

Termos para Indexação: pós-colheita, Musa sp., 1-metilciclopropeno, qualidade, amadurecimento

\section{ACTION OF 1-METHYLCYCLOPROPENE (1-MCP) ON SHELF LIFE OF ‘APPLE’ BANANA}

\begin{abstract}
The objective of this work was to evaluate the influence of the 1-MCP, at different concentrations, on quality and shelf life of 'Apple' banana. Green mature fruits were submitted to five concentrations of 1-MCP $\left(0,50,100,150\right.$ and $200 \eta L^{-1} L^{-1}$, for 12 hours $)$ and analyzed during the ripening at room temperature $\left(20^{\circ} \mathrm{C} \pm 1\right.$ and $\left.80 \% \pm 5 \mathrm{RH}\right)$. The 1-MCP at $50 \eta \mathrm{L} . \mathrm{L}^{-1}$ delayed, in 8 days, the begining of the ripening, based in the first changes of peel color, whereas 100, 150 and $200 \eta \mathrm{L} . \mathrm{L}^{-1}$ treatments delayed the begining of the ripening in 10 days, in comparison to the control. The softening of the fruits, associated to the conversion of starch in sugar and the increasing in the pectic solubilization and activity of pectinmethylsterase and polygalacturonase, was observed during the ripening. The application of $50 \eta \mathrm{L} . \mathrm{L}^{-1}$ of 1-MCP is the most proper for promoting the extension of shelf life of 'Apple' banana, keeping its quality based on total soluble sugar, total and soluble pectins, firmness analysis and external appearance in the end of storage.
\end{abstract}

Index Terms: postharvest, Musa sp., 1-methylcyclopropene, quality, ripening

\section{INTRODUÇÃO}

O Brasil é o segundo produtor mundial de banana, sendo superado pela Índia (FAO, 2004). Dentre as cultivares exploradas, a bananeira 'Maçã' (grupo AAB) salienta-se pelas ótimas características sensoriais de seus frutos e pela excelente aceitação destes no mercado consumidor, principalmente em Minas Gerais. A banana é um fruto climatérico que apresenta alta taxa respiratória e alta produção de etileno após a colheita, o que a torna altamente perecível. O etileno é um hormônio vegetal de estrutura simples que está envolvido em inúmeros processos, desde a germinação de sementes até o amadurecimento e senescência de frutos (Watkins, 2002). Este hidrocarboneto gasoso pode difundir-se dentro e fora dos tecidos vegetais, podendo afetar a qualidade de produtos hortículas, como cor, textura e flavor. Tais efeitos podem ser benéficos, como, por exemplo, em centrais de distribuição na uniformização de amadurecimento de vários produtos, ou deletérios, durante o armazenamento e transporte de frutos e hortaliças. O 1metilciclopropeno (1-MCP) é uma nova ferramenta que tem sido utilizada na extensão da vida pós-colheita e manutenção da qualidade de produtos vegetais (Blankenship \& Dole, 2003; Botrel et al., 2002; Harris et al., 2000; Golding et al., 1998). Em condições normais, o etileno liga-se a moléculas receptoras, provavelmente proteínas de membrana, de onde surgem respostas associadas ao amadurecimento. O 1-MCP liga-se a estes sítios receptores, inibindo a ação do etileno, retardando o processo de amadurecimento, já que novos sítios receptores são sintetizados, retornando a sensibilidade ao etileno. Liberado para utilização em produtos comestíveis em vários países, incluindo o Brasil, o 1-MCP é um produto promissor para utilização na pós-colheita de produtos vegetais. Este trabalho teve como objetivo avaliar o efeito do 1-MCP em diferentes concentrações sobre a vida pós-colheita e sob as variáveis associadas aos atributos de qualidade de banana 'Maçã'.

\section{MATERIAL E MÉTODOS}

Frutos da bananeira cv. Maçã foram adquiridos em uma lavoura localizada no município de Lavras-MG, no estádio 2 de coloração da casca (verde-maturo). Foram transportados para o Laboratório de Bioquímica de Frutos do Departamento de Ciência dos Alimentos da Universidade Federal de Lavras um dia após colhidos. Foram utilizadas 5 concentrações do produto 1-metilciclopropeno (1-MCP) na formulação pó, com 0,14\% de ingrediente ativo: 0 (controle); 50; 100; 150 e 200 ๆL.L${ }^{1}$. A aplicação foi realizada em caixas de isopor herméticas com volume de 100 litros, nas quais os frutos permaneceram por 12 horas. Os frutos, após aplicação, foram armazenados sob condição ambiente (temperatura média $20 \pm 1^{\circ} \mathrm{C}$ e umidade relativa $80 \pm 5 \%$ ) e avaliados à medida que atingiam os graus 3; 5 e 7 de coloração da casca, sendo o grau 3 definido como frutos com coloração da casca 50\% verde e 50\% amarela; grau 5, frutos com coloração amarela e extremidades ainda verdes, e grau 7 , completamente amarelos com manchas marrons. O experimento foi conduzido seguindo um delineamento inteiramente casualizado (DIC), com 15 tratamentos, ou seja, três graus de coloração da casca e cinco concentrações de 1-MCP, com 3 repetições. As parcelas foram constituídas de 3 buquês com 4 frutos. As análises estatísticas foram realizadas por meio do Teste de Tukey, a 5\%. Foram realizadas as seguintes análises:

Vida de prateleira: observando-se o número de dias gastos para a ocorrência das primeiras mudanças visíveis, de verde para amarelo, na casca, e desenvolvimento dos respectivos graus de coloração da casca dos frutos (grau 3; 5 e 7)

Amido: doseado segundo o método de Somogy, adaptado por Nelson (1944). A determinação foi feita a 620nm e os resultados expressos em $\mathrm{g}$ de glicose por $100 \mathrm{~g}$ de polpa fresca.

Açúcares solúveis totais (AST): extraídos com álcool etílico e

\footnotetext{
${ }^{1}$ (Trabalho 100/2004). Recebido: 04/08/2004. Aceito para publicação: 09/03/2005.

2 Doutoranda em Ciência dos Alimentos/ Universidade Federal de Lavras-MG. ana.carla@ posgrad.br

${ }^{3}$ Professor Adjunto da Universidade Federal de Lavras evbvboas@ufla.br

${ }^{4}$ Engenheira Agrônoma.
} 
TABELA 1 - Média do número de dias gastos para a ocorrência das primeiras mudanças de coloração da casca e desenvolvimento dos respectivos graus de coloração da casca em bananas 'Maçã', submetidas a tratamento com 1-metilciclopropeno (1-MCP) em diferentes concentrações, por 12 horas, e armazenadas sob condição ambiente $\left(20 \pm 1^{\circ} \mathrm{C}\right.$ e $80 \pm 5 \%$ UR).

\begin{tabular}{|c|c|c|c|c|c|c|c|}
\hline \multirow{3}{*}{$1-\mathrm{MCP}\left(\mathrm{L} \cdot \mathrm{L}^{-1}\right)$} & \multirow{3}{*}{$\begin{array}{l}\text { PRIMEIRAS MUDANÇAS } \\
\text { DE COLORAÇÃO DA } \\
\text { CASCA (DIA) }\end{array}$} & \multicolumn{6}{|c|}{ GRAUS DE COLORAÇÃO DA CASCA } \\
\hline & & \multirow{2}{*}{\multicolumn{2}{|c|}{ G3 }} & \multicolumn{2}{|c|}{ G5 } & \multicolumn{2}{|c|}{ G7 } \\
\hline & & & & \multicolumn{2}{|c|}{$\mathbf{N}^{0}$ DE DIAS } & & \\
\hline 0 (controle) & $6,75 \quad 2,99$ & 7,6 & 2,94 & 9,15 & 3,77 & 13,44 & 3,88 \\
\hline 50 & $15,02 \quad 1,8$ & 16,93 & 2,11 & 18,67 & 1,76 & 22,63 & 1,56 \\
\hline 100 & $17,03 \quad 2,85$ & 20,53 & 2,57 & 23,95 & 2,87 & 29,18 & 2,32 \\
\hline 150 & $17,27 \quad 2,96$ & 20,64 & 2,77 & 24,22 & 3,54 & 29,78 & 1,68 \\
\hline 200 & $16,81 \quad 2,86$ & 20,03 & 2,68 & 24,18 & 2,91 & 29,88 & 1,96 \\
\hline
\end{tabular}

Graus de coloração da casca: G3- 50\% verde e 50\% amarela; G5- coloração amarela com extremidades ainda verdes; G7- completamente amarelas com manchas marrons.

determinados pelo método da antrona (Dische, 1962). Os resultados foram expressos em gramas de glicose por $100 \mathrm{~g}$ de polpa.

Firmeza da polpa: medida após a retirada da casca, com penetrômetro Mc-Cormick, com ponta de diâmetro $8 \mathrm{~mm}$. Os resultados foram expressos em $\mathrm{N}$.

Pectinas total (PT) e solúvel (PS): foram extraídas segundo a técnica descrita por McCready \& McComb (1952) e determinadas colorimetricamente segundo Bitter \& Muir (1962). Os resultados foram expressos em mg de ácido galacturônico por $100 \mathrm{~g}$ de polpa.

Atividade da pectinametilesterase: a extração da pectinametilesterase (PME) foi realizada segundo a técnica de Buescher \& Furmanski (1978), e o doseamento foi realizado segundo Hultin et al. (1966) e Ratner et al. (1969), com modificações de Vilas Boas (1995). Uma unidade de PME foi definida como a quantidade de enzima capaz de catalisar a desmetilação de pectina correspondente ao consumo de 1 $\eta$ mol de $\mathrm{NaOH}$ por grama de polpa fresca.min.

Atividade da poligalacturonase: a extração da poligalacturonase (PG) foi realizada segundo a técnica de Buescher \& Furmanski (1978), e o doseamento foi realizado segundo Markovic et al. (1975), com modificações de Vilas Boas (1995). A atividade enzimática foi expressa em $\eta$ mol de açúcar redutor por grama de polpa fresca.min.

\section{RESULTADOSE DISCUSSÃO}

A aplicação de $50 \eta L^{L} L^{-1}$ de 1-MCP atrasou, visualmente, o início do amadurecimento em aproximadamente 8 dias, baseando-se nas primeiras mudanças de coloração da casca, enquanto os demais tratamentos (100; 150 e $200 \eta \mathrm{L} . \mathrm{L}^{-1}$ de 1-MCP) atrasaram este início em aproximadamente 10 dias, em comparação ao controle (Tabela 1). Após ocorridas as primeiras mudanças na coloração da casca, a diferença entre o tempo necessário para que os frutos submetidos a $50 \eta \mathrm{L} . \mathrm{L}^{-1}$ de 1 MCP e para que os frutos-controle atingissem os graus 3; 5 e 7 de coloração da casca, permaneceu constante, em torno de 9 dias. A diferença entre os submetidos aos demais tratamentos e os do controle aumentou ao longo do amadurecimento, atingindo 13; 15 e 16 dias, nos graus 3; 5 e 7 de coloração da casca, respectivamente. Observando-se esses resultados, nota-se que os tratamentos com 100; 150 e $200 \eta L^{2} L^{-1}$ atrasaram não só o início como todo o processo de amadurecimento dos frutos, enquanto o tratamento $50 \eta \mathrm{L} . \mathrm{L}^{-1}$ atrasou somente o início do amadurecimento. Botrel et al. (2002), trabalhando com bananas da cultivar Prata-Anã, submetidas ao 1-MCP e armazenadas a $24^{\circ} \mathrm{C}$ e $78,5 \%$ UR, detectaram também a eficiência do produto no retardo do amadurecimento.

Notou-se, ao longo do amadurecimento, amarelecimento desuniforme da casca dos frutos submetidos a $100 ; 150$ e $200 \eta L^{2} L^{-1}$ (dados não mostrados) e uma aparência comprometida destes ao final do armazenamento.

Observou-se, durante o amadurecimento, a despeito da aplicação de 1-MCP, o amaciamento dos frutos, associado à conversão de amido em açúcares e ao aumento na solubilização péctica e na atividade das enzimas pécticas, $\mathrm{PME}$ e $\mathrm{PG}$.
Os frutos sob efeito do 1-MCP, nos graus 5 e 7 de coloração da casca, apresentaram firmeza da polpa igual à dos frutos-controle, o que sugere o benéfico efeito do inibidor da ação do etileno na prevenção do amaciamento da polpa da banana 'Maçã' durante seu armazenamento, considerando-se sua maior vida de prateleira (Tabela 2). Acredita-se que o 1-MCP, ligando-se ao sítio receptor do etileno, retarde a ativação de enzimas associadas ao amaciamento.

TABELA 2 - Firmeza (N) da polpa de bananas 'Maçã, submetidas a tratamentos com 1-MCP em diferentes concentrações, por 12 horas, e armazenadas sob condição ambiente $\left(20 \pm 1^{\circ} \mathrm{C}\right.$ e $80 \pm 5 \%$ UR).

\begin{tabular}{c|ccc}
\hline \multirow{2}{*}{ 1-MCP $\left(\right.$ L.L $\left.^{-1}\right)$} & \multicolumn{3}{|c}{ GRAUS DE COLORAÇÃO DA CASCA } \\
\cline { 2 - 4 } & G3 & G5 & G7 \\
\cline { 2 - 4 } & \multicolumn{3}{|c}{ Firmeza (N) } \\
\hline $\mathbf{0}$ (controle) & $17,3 \mathrm{c}$ & $10,76 \mathrm{a}$ & $5,92 \mathrm{a}$ \\
$\mathbf{5 0}$ & $14,50 \mathrm{bc}$ & $9,39 \mathrm{a}$ & $6,58 \mathrm{a}$ \\
$\mathbf{1 0 0}$ & $13,03 \mathrm{ab}$ & $10,63 \mathrm{a}$ & $6,85 \mathrm{a}$ \\
$\mathbf{1 5 0}$ & $12,99 \mathrm{ab}$ & $10,36 \mathrm{a}$ & $8,05 \mathrm{a}$ \\
$\mathbf{2 0 0}$ & $10,99 \mathrm{a}$ & $10,01 \mathrm{a}$ & $7,70 \mathrm{a}$ \\
\hline
\end{tabular}

Médias seguidas de, pelo menos, uma mesma letra, na coluna, são iguais entre si, pelo teste de Tukey $(\mathrm{p}>0,05)$. Graus de coloração da casca: G3- 50\% verde e $50 \%$ amarela; G5- coloração amarela com extremidades ainda verdes; G7completamente amarelas com manchas marrons.

TABELA 3 - Teores de amido (g glicose . $100 \mathrm{~g}^{-1}$ ) e açúcares solúveis totais (g glicose . $100 \mathrm{~g}^{-1}$ ) em bananas 'Maçã', submetidas a tratamentos com 1-MCP em diferentes concentrações,

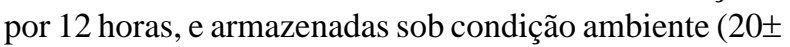
$1{ }^{\circ} \mathrm{Ce} 80 \pm 5 \%$ UR).

\begin{tabular}{|c|c|c|c|}
\hline \multirow[b]{3}{*}{$1-\mathrm{MCP}\left(\mathrm{L}_{\mathrm{L}} \mathrm{L}^{-1}\right)$} & \multicolumn{3}{|c|}{ GRAUS DE COLORAÇÃO DA CASCA } \\
\hline & G3 & G5 & G7 \\
\hline & \multicolumn{3}{|c|}{ Amido (g glicose $\left..100 g^{-1}\right)$} \\
\hline 0 (controle) & $18,36 \mathrm{c}$ & $9,94 \mathrm{c}$ & $3,24 \mathrm{a}$ \\
\hline 50 & $16,00 \mathrm{~b}$ & $7,27 \mathrm{~b}$ & $3,43 \mathrm{a}$ \\
\hline 100 & $17,37 \mathrm{c}$ & $5,39 \mathrm{a}$ & $3,20 \mathrm{a}$ \\
\hline 150 & $14,99 \mathrm{~b}$ & $6,25 \mathrm{ab}$ & $4,52 b$ \\
\hline \multirow[t]{2}{*}{200} & $13,84 \mathrm{a}$ & $5,82 \mathrm{a}$ & $3,32 \mathrm{a}$ \\
\hline & \multicolumn{3}{|c|}{ Açúcares Solúveis Totais (g glicose . $\left.100 \mathrm{~g}^{-1}\right)$} \\
\hline 0 (controle) & $7,82 \mathrm{a}$ & $11,20 \mathrm{a}$ & $19,22 b$ \\
\hline 50 & $9,53 \mathrm{ab}$ & $13,36 \mathrm{ab}$ & $18,62 \mathrm{ab}$ \\
\hline 100 & $11,22 b$ & $14,44 b c$ & $17,22 \mathrm{ab}$ \\
\hline 150 & $11,15 b$ & $15,86 \mathrm{c}$ & $16,79 \mathrm{a}$ \\
\hline 200 & 9,99ab & $14,45 \mathrm{bc}$ & $16,57 \mathrm{a}$ \\
\hline
\end{tabular}

Médias seguidas de, pelo menos, uma mesma letra, na coluna, são iguais entre si, pelo teste de Tukey ( $\mathrm{p}>0,05)$. Graus de coloração da casca: G3- 50\% verde e $50 \%$ amarela; G5- coloração amarela com extremidades ainda verdes; G7completamente amarelas com manchas marrons. 
Uma das mais flagrantes modificações durante o amadurecimento de bananas é a hidrólise do amido, que culmina com o acúmulo de açúcares e adoçamento da polpa (Vilas Boas et al., 2001). Observaram-se maiores teores de amido nos frutos-controle, quando comparados aos frutos submetidos ao 1-MCP, nos graus 3 e 5 e, no grau 7, notaram-se valores semelhantes entre o controle e os tratados com 1MCP, com exceção do $150 \eta L^{2} L^{-1}$. Com relação aos açúcares solúveis totais (AST), observaram-se menores teores no controle e no $50 \mathrm{~nL} . \mathrm{L}^{-1}$ de 1-MCP, nos graus 3 e 5 e uma pequena variação nos ASTs, entre o controle e os demais tratamentos, no grau 7. Golding et al. (1998), trabalhando com bananas cv. Willians, também encontraram concentrações similares de AST, no grau 7, de coloração da casca, entre os frutos tratados com $45 \mu \mathrm{L} \mathrm{L}^{-1}$ de 1-MCP e os frutos-controle.

Verificou-se uma ascensão nos níveis de pectina solúvel (PS) com o avanço da maturação dos frutos, como já dito anteriormente (Tabela 4). O incremento no teor de PS observado durante o amadurecimento da banana 'Maçã' é condizente com os trabalhos de Kojima et al. (1994) e Vilas Boas et al. (1996), com outras cultivares. Pode-se fazer um paralelo entre este incremento nos teores de PS e a perda de firmeza da polpa durante o amadurecimento, já que o amaciamento está associado com a despolimerização de polissacarídeos pécticos, entre outros fatores. Kojima et al. (1994) também apresentam como causa principal do processo de amaciamento da polpa de banana, a degradação coordenada de polissacarídios pécticos, hemicelulósicos e de amido. Os frutos-controle, seguidos dos submetidos a $50 \eta \mathrm{L} . \mathrm{L}^{-1}$, em média, apresentaram menor solubilização de substâncias pécticas, quando comparados aos tratados com 100; 150 e $200 \eta L^{2} L^{-1}$ (Tabela 4). Ao final do armazenamento (grau 7), notou-se pequena variação no teor de PS entre os frutos tratados com 1MCP e o controle. Observou-se uma tendência de queda nos teores de pectina total (PT) nas concentrações 100 e 150 ๆL.L-1 de 1-MCP durante o amadurecimento e de estabilidade nos demais tratamentos. Notou-se diferença na concentração de PT somente entre o 100 ๆL.L $\mathrm{L}^{-1}$ e o controle, no grau 3 e, nos graus 5 e 7, não se observaram diferenças entre o controle e os submetidos ao 1-MCP (Tabela 5). Foram observados menores valores para a atividade da pectinametilesterase (PME) nos frutos tratados com 1-MCP, no grau 7 de coloração da casca. Nenhuma diferença foi observada no grau $3 \mathrm{e}$, no grau 5, o tratamento $100 \eta \mathrm{L}^{-L^{-1}}$ determinou a maior atividade da enzima (Tabela 6). Notou-se, em média, maior atividade da poligalacturonase (PG) nos frutos tratados com 100; 150 e $200 \eta L . L^{-1}$ de 1-MCP, seguido do tratamento com $50 \eta L . L^{-1}$. Estes resultados podem ser associados aos observados na PS, pois a PG é a enzima responsável pela despolimerização de substâncias pécticas, originando monômeros de ácidos galacturônicos, denominados fração solúvel das substâncias pécticas.

Sugere-se que as diferenças, nas variáveis analisadas, nos graus $3 ; 5$ e 7 de coloração da casca, principalmente entre os frutos submetidos a 100; 150 e $200 \eta L^{-L^{-1}}$ e o controle sejam devidas ao desverdecimento desuniforme, que dificultou a observação visual dos respectivos graus de coloração (graus $3 ; 5$ e 7).

TABELA 4 - Pectina solúvel (mg ácido galacturônico. $100 \mathrm{~g}^{-1}$ polpa) em bananas 'Maçã', submetidas a tratamentos com 1-MCP em diferentes concentrações, por 12 horas, e armazenadas sob condição ambiente $\left(20 \pm 1{ }^{\circ} \mathrm{C}\right.$ e $80 \pm 5 \%$ UR).

\begin{tabular}{c|ccc}
\hline \multirow{2}{*}{} & \multicolumn{3}{|c}{ GRAUS DE COLORAÇÃO DA } \\
CASCA \\
\cline { 2 - 4 } 1-MCP $\left(\right.$ L.L $\left.^{-1}\right)$ & $\mathbf{G 3}$ & $\mathbf{G 5}$ & $\mathbf{G 7}$ \\
\hline $\mathbf{0}$ (controle) & $161,46 \mathrm{a}$ & $239,38 \mathrm{a}$ & $326,53 \mathrm{a}$ \\
$\mathbf{5 0}$ & $190,46 \mathrm{ab}$ & $293,9 \mathrm{~b}$ & $315,22 \mathrm{a}$ \\
$\mathbf{1 0 0}$ & $213,69 \mathrm{bc}$ & $327,8 \mathrm{~b}$ & $330,25 \mathrm{a}$ \\
$\mathbf{1 5 0}$ & $262,27 \mathrm{~cd}$ & $284,99 \mathrm{ab}$ & $358,43 \mathrm{ab}$ \\
$\mathbf{2 0 0}$ & $266,47 \mathrm{~d}$ & $323,96 \mathrm{~b}$ & $386,68 \mathrm{~b}$ \\
\hline
\end{tabular}

Médias seguidas de, pelo menos, uma mesma letra, na coluna, são iguais entre si, pelo teste de Tukey ( $p>0,05)$. Graus de coloração da casca: G3- 50\% verde e 50\% amarela; G5- coloração amarela com extremidades ainda verdes; G7completamente amarelas com manchas marrons.
TABELA 5 - Pectina total (mg ácido. galacturônico. $100 \mathrm{~g}^{-1}$ ) em bananas 'Maçã,' submetidas a tratamentos com 1-MCP em diferentes concentrações, por 12 horas, e armazenadas sob condição ambiente $\left(20 \pm 1^{\circ} \mathrm{C}\right.$ e $80 \pm 5 \%$ UR).

\begin{tabular}{c|ccc}
\hline \multirow{2}{*}{ 1-MCP $\left(\right.$ L.L $\left.^{-1}\right)$} & \multicolumn{3}{|c}{ GRAUS DE COLORAÇÃO DA } \\
\cline { 2 - 4 } CASCA \\
\hline $\mathbf{0}$ (controle) & G3 & G5 & G7 \\
$\mathbf{5 0}$ & $490,54 \mathrm{ab}$ & $464,46 \mathrm{ab}$ & $424,74 \mathrm{a}$ \\
$\mathbf{1 0 0}$ & $497,27 \mathrm{ab}$ & $528,43 \mathrm{~b}$ & $426,21 \mathrm{a}$ \\
$\mathbf{1 5 0}$ & $513,21 \mathrm{~b}$ & $385,58 \mathrm{a}$ & $385,72 \mathrm{a}$ \\
$\mathbf{2 0 0}$ & $500,66 \mathrm{ab}$ & $406,64 \mathrm{a}$ & $419,13 \mathrm{a}$ \\
& $409,53 \mathrm{a}$ & $433,52 \mathrm{ab}$ & $440,07 \mathrm{a}$ \\
\hline
\end{tabular}

Médias seguidas de, pelo menos, uma mesma letra, na coluna, são iguais entre si, pelo teste de Tukey $(\mathrm{p}>0,05)$. Graus de coloração da casca: G3- 50\% verde e 50\% amarela; G5- coloração amarela com extremidades ainda verdes; G7completamente amarelas com manchas marrons.

TABELA 6 - Atividade da pectinametilesterase ( $\eta$ mol NaOH. $\mathrm{g}^{-1}$ de polpa fresca. $\min ^{-1}$ ) em bananas 'Maçã', submetidas a tratamentos com 1-MCP em diferentes concentrações, por 12 horas, e armazenadas sob condição ambiente $\left(20 \pm 1^{\circ} \mathrm{C}\right.$ e $80 \pm 5 \%$ UR).

\begin{tabular}{|c|c|c|c|}
\hline \multirow{3}{*}{$1-\mathrm{MCP}\left(\mathrm{L} \cdot \mathrm{L}^{-1}\right)$} & \multicolumn{3}{|c|}{$\begin{array}{l}\text { GRAUS DE COLORAÇÃO DA } \\
\text { CASCA }\end{array}$} \\
\hline & G3 & G5 & G7 \\
\hline & \multicolumn{3}{|c|}{ PME $\left(\mathrm{mol} \cdot \mathrm{g}^{-1} \cdot \mathrm{min}^{-1}\right)$} \\
\hline 0 (controle) & $0,00 \mathrm{a}$ & $433,33 a$ & $1.366,67 d$ \\
\hline 50 & $66,67 \mathrm{a}$ & $483,33 \mathrm{ab}$ & $966,67 \mathrm{c}$ \\
\hline 100 & $166,67 \mathrm{a}$ & $650,00 \mathrm{~b}$ & $966,67 \mathrm{c}$ \\
\hline 150 & $66,67 \mathrm{a}$ & $336,66 a$ & $533,33 a$ \\
\hline 200 & $33,33 \mathrm{a}$ & $350,00 \mathrm{a}$ & $733,33 b$ \\
\hline
\end{tabular}

Médias seguidas de, pelo menos, uma mesma letra, na coluna, são iguais entre si, pelo teste de Tukey ( $\mathrm{p}>0,05$ ). Graus de coloração da casca: G3- 50\% verde e $50 \%$ amarela; G5- coloração amarela com extremidades ainda verdes; G7completamente amarelas com manchas marrons.

TABELA 7 - Atividade da poligalacturonase ( $\eta$ mol açúcar redutor . $\mathrm{g}^{-1}$ de polpa fresca . min $^{-1}$ ) em bananas 'Maçã', submetidas a tratamentos com 1-MCP em diferentes concentrações, por

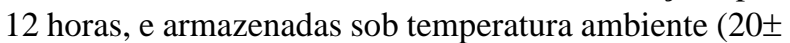
$1{ }^{\circ} \mathrm{Ce} 80 \pm 5 \%$ UR).

\begin{tabular}{|c|c|c|c|c|}
\hline \multirow{3}{*}{$1-\mathrm{MCP}\left(\mathrm{L} \cdot \mathrm{L}^{-1}\right)$} & \multicolumn{3}{|c|}{$\begin{array}{c}\text { GRAUS DE COLORAÇÃO DA } \\
\text { CASCA }\end{array}$} & \multirow[b]{3}{*}{ Médias } \\
\hline & G3 & G5 & G7 & \\
\hline & \multicolumn{3}{|c|}{ PG $\left(\mathrm{mol} \cdot \mathrm{g}^{-1} \cdot \mathrm{min}^{-1}\right)$} & \\
\hline 0 (controle) & $11,54 \mathrm{~ns}$ & $16,66 \mathrm{~ns}$ & $73,29 \mathrm{~ns}$ & 33,83a \\
\hline 50 & $17,24 \mathrm{~ns}$ & $24,08 \mathrm{~ns}$ & $78,58 \mathrm{~ns}$ & $39,96 b$ \\
\hline 100 & $25,46 \mathrm{~ns}$ & $27,61 \mathrm{~ns}$ & $86,97 \mathrm{~ns}$ & $46,68 \mathrm{c}$ \\
\hline 150 & $24,64 \mathrm{~ns}$ & $25,06 \mathrm{~ns}$ & $89,73 \mathrm{~ns}$ & $46,48 \mathrm{c}$ \\
\hline 200 & $19,96 \mathrm{~ns}$ & $22,98 \mathrm{~ns}$ & $84,22 \mathrm{~ns}$ & $42,39 \mathrm{bc}$ \\
\hline Médias & $19,77 \mathbf{a}$ & $23,28 b$ & $82,56 c$ & \\
\hline
\end{tabular}

Médias seguidas de, pelo menos, uma mesma letra, na coluna, são iguais entre si, pelo teste de Tukey ( $p>0,05$ ). Graus de coloração da casca: G3- 50\% verde e $50 \%$ amarela; G5- coloração amarela com extremidades ainda verdes; G7completamente amarelas com manchas marrons.

\section{AGRADECIMENTOS}

Ao CNPq e à Fapemig.

\section{CONCLUSÕES}

1. O 1-MCP a $50 \eta \mathrm{L} . \mathrm{L}^{-1}$ atrasa o início do amadurecimento de bananas 'Maçã', armazenadas sob condição ambiente $\left(20 \pm 1^{\circ} \mathrm{C}\right.$ e $80 \pm 5 \%$ UR), baseando-se nas primeiras mudanças visíveis de coloração de verde 
para amarela, em aproximadamente 8 dias, enquanto as concentrações $100 ; 150$ e $200 \eta$ $\eta . L^{-1}$ atrasam em aproximadamente 10 dias.

2. A aplicação de 1-MCP é a mais adequada, por promover a extensão da vida pós-colheita de bananas 'Maçã', preservando sua qualidade, com base nas análises de açúcares solúveis totais, pectinas total e solúvel, firmeza e aparência externa ao final do armazenamento.

\section{REFERÊNCIAS}

BITTER, T. MUIR, H. M. A modified uronic acid carbazole reaction. Analytical Biochemistry, New York, v. 4, n. 4, p. 330-334, 1962.

BLANKENSHIP, S. M.; DOLE, J. M. 1-Methylcyclopropene: a review. Postharvest Biology and Technology, Amsterdam, v. 28, n. 1, p. 1-25, apr. 2003.

BOTREL, N.; FREIRE, M. J.; VASCONCELOS, R. M.;BARBOSA, H.T. G Inibição do amadurecimento de banana 'Prata-Anã' com a aplicação do 1-Metilciclopropeno. Revista Brasileira de Fruticultura, Jaboticabal, v. 24, n. 1, p. 53-56, abr.. 2002.

BUESCHER, R. W.; FURMANSKI, R. J. Role of pectinesterase and polygalacturonase in the formation of woolliness in peaches. Journal of Food Science, Chicago, v. 43, n. 1, p. 264-266, jan./feb. 1978.

DISCHE, Z. General color reactions. In: WHISTLER, R. L.; WOLFRAM, M. L. Carbohydrate chemistry. New York: Academic Press, 1962.p. 477-512.

FAO. FOOD AND AGRICULTURE ORGANIZATION. Disponivel em: <http://apps.fao.org>. Acesso em: 10 fev. 2004.

GOLDING, J. B.; SHEARER, D.; WYLLIE, S. G. , McGLASSON, W. B. Application of 1-MCP and propylene to identify ethylene-dependent ripening processes in mature banana fruit. Postharvest Biology and Technology, Amsterdam, v. 14, n. 1, p. 87-98, sept. 1998.

HARRIS, D. R.; SEBERRY, J. A.; WILLS, L. J.; SPOHR, L. J. Effect of fruit maturity on efficiency of 1-methylcyclopropene to delay the ripening of bananas. Postharvest Biology and Technology, Amsterdam, v. 20, n. 3, p. 303-308, nov. 2000.
HULTIN, H. O.; SUN, B.; BULGER, J. Pectin methyl esterases of the banana. Purification and properties. Journal of Food Science, Chicago, v. 31, n. 3, p. 320-327, may/june 1966.

KOJIMA, K.; SAKURAI, N.; KURAISHI, S. Fruit softening in banana: correlation among stress-relaxation parameters, cell wall componentes and starch during ripening. Physiologia Plantarum, Copenhagen, v. 90, n. 4, p. 772-778, 1994.

MARKOVIC, O.; HEINRICHOVÁ, K.; LENKEY, B. Pectolytic enzymes from banana. Collection Czechoslovak Chemistry Community, London, v. 40, n. 3, p. 769-774, 1975.

McCREADY, R. M.; McCOMB, E. A. Extraction and determination of total pectic materials in fruit. Analytical Chemistry, Washington, v. 24, n. 12, p. 1586-1588, dec. 1952.

NELSON, N. A. A photometric adaptation of Somogyi method for the determination of glucose. The Journal of Biological Chemistry, Baltimore, v. 135, p. 135-375, 1944.

RATNER, A.; GOREN, R.; MONSELINE, S. P. Activity of pectin esterase and cellulase in the abcission zone of citrus leaf explants. Plant Physiology, Washington, v. 44, n. 12, p. 1717-1723, dec. 1969.

VILAS BOAS, E. V. B. Modificações pós-colheita de bananas 'Prata' (Musa acuminata x Musa balbisiana Grupo AAB) $\gamma$-irradiada. 1995. 73f. Dissertação (Mestrado em Ciência dos Alimentos) Universidade Federal de Lavras, Lavras-MG, 1995.

VILAS BOAS, E.V.B.; ALVES, R.E.; FILGUEIRAS, H.A.C.; MENEZES, J.B. Características da fruta: banana pós-colheita. Brasília: EMBRAPA, 2001. p. 15-19. (Série Frutas do Brasil, 16).

VILAS BOAS, E. V. B.; CHITARRA, A. B.; CHITARRA, M. I. F. Modificações pós-colheita de bananas 'Prata' $\gamma$-irradiada. Pesquisa Agropecuária Brasileira, Brasília, v. 31, n. 9, 1996.

WATKINS, C. B. Ethylene synthesis, mode of action, consequences and control. In: KNEE, M. Fruit quality and its biological basis. Columbus, Ohio: CRC Press, 2002.279p. 